\title{
Epidemiological study of heterophyiasis among humans in an area of Egypt
}

L.M. Abou-Basha, ${ }^{\top}$ M. Abdel-Fattah, ${ }^{2}$ P. Orecchia, ${ }^{3}$ D. Di Cave ${ }^{3}$ and A. Zaki ${ }^{2}$

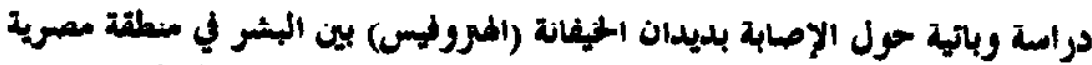

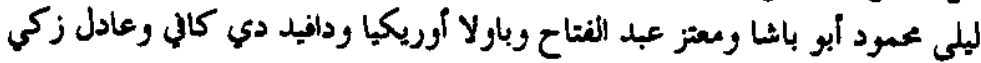

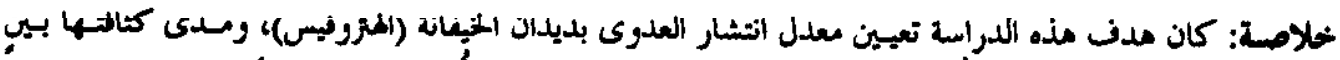

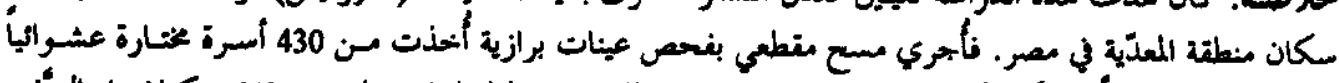

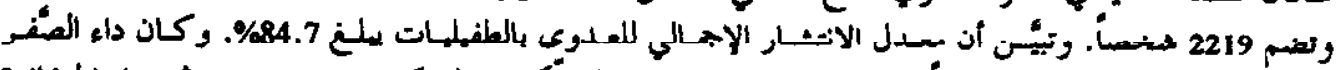

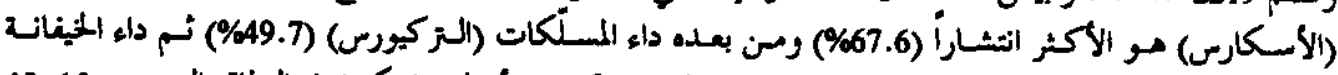

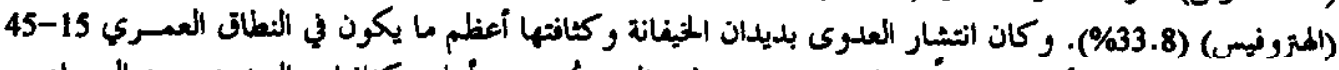

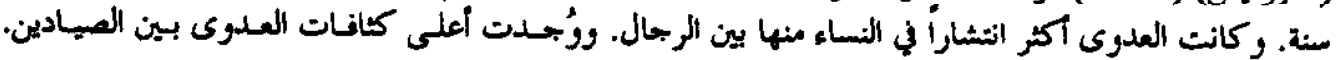

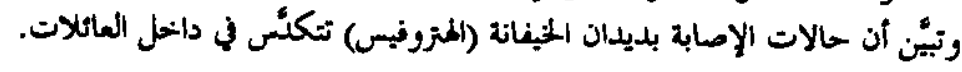

ABSTRACT We aimed to determine the prevalence and intensity of infection of heterophyiasis among inhabitants of El-Meaddeya, Egypt. A cross-sectional stool examination survey was performed on 430 randomly chosen households, comprising 2219 Indivlduals. The overall prevalence of parasitic infection was $84.7 \%$. Ascariosis was the most common $(67.6 \%)$, followed by trichuriosis $(49.7 \%)$ and heterophyiasis (33.8\%). The prevalence and intensity of infection of heterophyiasis were most common in people 15-45 years, and greater in females than males. The highest intensity of infection was detected amono fishemen. Intrafamilial aggregation of cases of heterophyiasis was identified.

\section{Etude épldémiologlque de l'hótérophyase chez l'homme dans une région d'Egypte}

RESUME Notre objoctif était de dóterminer la próvalence et lintensité de l'hétérophyase chez des habltants d'El-Meaddeya (Egypte). Un examen transversal des selles a été réalisé dans 430 ménages choisis au hasard, comprenant 2219 individus. La prévalence globale de l'infection parasitaire était de 84,7\%. L'ascaridiase était la plus courante $(67,6 \%)$, suivie par la trichocéphalose $(49,7 \%)$ et l'hétérophyase $(33,8 \%)$. La prévalence er lintensité de l'netérophyase étaient plus courantes chez les personnes ágées de 15 à 45 ans et plus tortes chez les femmes que chez les hommes. La plus forte intensité de l'infection a été détectée chez les pécheurs. L'agrégation intrafamiliale des cas d'hétérophyase a été identifiée. \footnotetext{
'Department of Parasitology; ${ }^{2}$ Department of Medical Statistics, Medical Research Institute, University of
Alexandria, Alexandria, Egypt.

'Dipartimento di Sanita'Pubblica e Biologia Cellulare, Universita Tor Vergata, Rome, Italy.

Feceived: 00/7 7/00; accepted: 02/05/00
} 


\section{Introduction}

Heterophyiasis is due to infection by very minute flukes called heterophoids. The adults live in the upper part of the small intestine embedded in mucus and mucosal folds. Heavy infection can cause abdominal pain and diarrhoea $[I]$. Heterophyiasis has been endemic in humans in the Nile Delta for decades [2].

Infection is acquired by eating raw fish, a common food in areas of heavy endemicity [3]. In endemic areas, people who live near lake shores or river banks usually have a higher rate and intensity of infection than those living a distance from such areas. It is possible that inhabitants of these areas eat more low-salted or improperly cooked fish, and that their fish are obtained from polluted water. It is common practice for people to defecate on the lake shores and river banks or from their boats while fishing, thus, perpetuating the cycle of infection $[2,4]$

Lake Edku is the smallest lake situated north of the Nile Delta. It is directly connected to the Mediterranean Sea at the western extremity through a narrow channel called Boughaz El-Meaddeya. The lakesea connection is located in the inner part of a partially sheltered bay known as Abu Qir. Lake Edku lies west of the Rosetta branch of the River Nile, and extends from east to west for a distance of about $19 \mathrm{~km}$, with an average depth of about $1 \mathrm{~m}$.

Results of the European Community project carried out by the Department of Parasitology of the University of Alexandria revealed that Melania tuberculata snails and the grey mullet (Mugils) fish species Liza ramada and $L$. aurata found in ElMeaddeya village harbour larval stages (cercaria and metacercaria) of Heterophyes [5]. Our study was undertaken to determine the prevalence of human heterophyia- sis in El-Meaddeya village, which is suspected of being an endemic area, and to study the influence of some demographic characteristics on the intensity of the infection.

\section{Subjects and methods}

A map was prepared showing all of the houses (1292) in El-Meaddeya village in an area of $4 \mathrm{~km}$ in length. A frame for all houses was constructed and a systematic random sampling technique with a sampling proportion of 1:3 was applied. Occupants of 430 houses were asked to participate in the study. A short questionnaire was used to collect demographic data including individual's name, age, sex and occupation. They were also questioned about their habit of eating fish, including the type, size and method of cooking or processing.

Stool samples were collected from 2219 individuals and examined in the laboratory. Three different methods of stool examination were considered: simple sedimentation, formal ether and the Kato technique. The Kato technique was determined to be the most sensitive method, and the stools were examined only by this technique. It was used to determine the intensity of infection in the study population [6].

\section{Statistical methods}

Data were analysed using SPSS. The geometric mean egg count with a $95 \%$ confidence interval (CI) was calculated and presented in different subgroups. Significance of the differences between mean log egg counts was assessed using analysis of variation (ANOVA). In order to study the intrafamilial aggregation of cases, only families with more than three people examined were included ( $n=246$ families). The overall prevalence rate of Heterophyes infection in the study population was estimat-

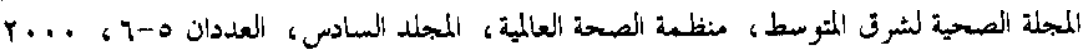


ed with a $95 \%$ CI. Frequency of Heterophyes infection in each family was calculated and families were divided into three different groups: group 1 included families with an infection rate within the $95 \% \mathrm{CI}$ of the average estimated prevalence in the total study population; groups 2 and 3 included families with frequency of infection below and above the $95 \% \mathrm{CI}$ respectively.

\section{Results}

The study included 2219 individuals, of whom 1027 were males $(46.3 \%)$ and 1192 $(53.7 \%)$ were females. Of the studied individuals, $13.7 \%$ were $<5$ years of age while $12.7 \%$ were $>45$ years. Housewives and fishermen constituted $28.0 \%$ and $16.5 \%$ of the study population respectively. The prevalence of parasitic infections in ElMcaddeya village was found to be relatively high, affecting $84.7 \%$ of the population. Ascaris lumbricoides and Trichuris trichiu$r a$ were the most frequent $(67.6 \%$ and $49.7 \%$ respectively), followed by $H$. heterophyes (33.8\%) as shown in Table 1. Regarding the patterns of eating fish, the participants ate all types and sizes of fish either grilled or salted for 1-2 days.

The highest prevalence of heterophyiasis was found in the age group $15-45$ years $(37.3 \%)$. Even in young children $<5$ years, heterophyiasis was unexpectedly high $(28.0 \%)$. It was more prevalent in females than in males $(36.7 \%$ versus $30.6 \%)$, and in those without work (46.9\%), housewives (35.9\%) and those working as fishermen $(35.8 \%)$ as shown in Table 2.

The intensity of heterophyiasis was highest in the age group 15-45 years (mean egg count 87.32, CI: 77.64-97.93). Intensity of infection was slightly higher in females (mean egg count $78.80, \mathrm{CI}$ : 71.35-87.02) as compared to males (mean
Table 1 Sociodemographic characterlstics of the study population $(n=2219)$ end their paresitic infection

\begin{tabular}{|c|c|c|}
\hline Characteristic & No. & $\%$ \\
\hline \multicolumn{3}{|l|}{ Age (years) $(n=2212)$} \\
\hline$\leq 5$ & 304 & 13.7 \\
\hline $5-14$ & 660 & 29.8 \\
\hline $\begin{array}{l}15-45 \\
>45\end{array}$ & $\begin{array}{l}968 \\
280\end{array}$ & $\begin{array}{l}43.8 \\
127\end{array}$ \\
\hline \multicolumn{3}{|l|}{$\operatorname{Sex}$} \\
\hline Male & 1027 & 46.3 \\
\hline Female & 1192 & 53.7 \\
\hline \multicolumn{3}{|l|}{ Occupation $(\mathrm{n}=2215)^{b}$} \\
\hline Unemployedc & 145 & 6.5 \\
\hline Housewife & 621 & 28.0 \\
\hline Student & 616 & 27.8 \\
\hline Fisherman & 366 & 16.5 \\
\hline Child (preschool) & 147 & 6.6 \\
\hline Others & 320 & 14.4 \\
\hline \multicolumn{3}{|l|}{ Parasitic infection ${ }^{\prime}$} \\
\hline Froe & 340 & 15.3 \\
\hline Ascaris lumbricoides & 1501 & 67.6 \\
\hline Trichuris trichiura & 1102 & 49.7 \\
\hline Heterophyes & 751 & 33.8 \\
\hline Hymenolepis nana & 19 & 0.9 \\
\hline Fasciola hepatica & 18 & 0.8 \\
\hline Schistocome mansoni & $\boldsymbol{\infty}$ & 1.5 \\
\hline
\end{tabular}

- Seven cases with missed age.

${ }^{\circ}$ Four cases with missed occupation.

'Both sexos.

The sum does not add up to the total number examined because one individual can harbour more than one parasitic infection.

egg count 74.32, CI: 66.09-83.57). Fishermen had the highest intensity of heterophyiasis with a mean egg count of 95.46 , CI: 78.32-116.33 as shown by Table 3 .

Figure 1 shows that in $27.0 \%$ of families, all family members were free of heterophyiasis and in $48.0 \%$ of families, two or more individuals in the same family were infected. Only in $25.0 \%$ of the studied families was only one person infected $\left(\chi_{13}^{2}=\right.$ 243.5, $P<0.0001$ ). 
Table 2 Heterophold infection by sociodemographic characteristics of the study population

\begin{tabular}{|c|c|c|c|c|c|c|c|}
\hline \multirow[t]{3}{*}{ Characterlstic } & \multicolumn{6}{|c|}{ Heterophoid Infection } & \multirow[t]{3}{*}{$\chi^{2}(P$-value $)$} \\
\hline & \multicolumn{2}{|c|}{ Total infected } & \multicolumn{2}{|c|}{ Single } & \multicolumn{2}{|c|}{ Mixed } & \\
\hline & No. & $\%$ & No. & $\%$ & No. & $\%$ & \\
\hline \multicolumn{8}{|l|}{ Age (years) } \\
\hline$<5(n=304)$ & 85 & 28.0 & 18 & 5.9 & 67 & 22.0 & $19.7(0.003)$ \\
\hline $5-14(n=660)$ & 222 & 33.6 & 29 & 4.4 & 193 & 29.2 & \\
\hline $15-45(n=968)$ & 361 & 37.3 & 68 & 7.0 & 293 & 30.3 & \\
\hline$>45(n=280)$ & 76 & 27.1 & 14 & 5.0 & 62 & 22.1 & \\
\hline \multicolumn{8}{|l|}{ Sax } \\
\hline Male $(n=1027)$ & 314 & 30.6 & 59 & 5.7 & 255 & 24.8 & $10.1(0.006)$ \\
\hline Female $(n=1192)$ & 437 & 36.7 & 70 & 5.9 & 367 & 30.8 & \\
\hline \multicolumn{8}{|l|}{ Occupationt } \\
\hline Unemployed $(n=145)^{\circ}$ & 68 & 46.9 & 10 & 6.9 & 58 & 40.0 & $29.5(0.001)$ \\
\hline Housewife $(n=621)$ & 223 & 35.9 & 32 & 5.2 & 191 & 30.8 & \\
\hline Student $(n=616)$ & 192 & 31.2 & 28 & 4.5 & 164 & 26.6 & \\
\hline Fisherman $(n=366)$ & 131 & 35.8 & 28 & 7.7 & 103 & 28.1 & \\
\hline Child (preschool) $(n=147)$ & 38 & 25.9 & 11 & 7.5 & 27 & 18.4 & \\
\hline Others $(n=320)$ & 95 & 29.7 & 20 & 6.3 & 75 & 23.4 & \\
\hline
\end{tabular}

- Seven cases with missed ape.

bFour cases with missed occupation.

Eoth sexes.

Table 3 Intensity of heterophoid infectlon according to the sociodemographic characteristics of studied cases"

\begin{tabular}{|c|c|c|c|c|}
\hline Characteristic & No. & $\begin{array}{c}\text { Geometric mean } \\
\text { of egg count }\end{array}$ & $\begin{array}{l}95 \% \text { confldence } \\
\text { intervale }\end{array}$ & $\begin{array}{l}\text { Statist/cal } \\
\text { data }\end{array}$ \\
\hline \multicolumn{5}{|l|}{$A g \theta$ (years $)^{b}$} \\
\hline$<5$ & 85 & 59.58 & $49.50-71.70$ & \multirow{4}{*}{$\begin{array}{c}F_{(3,740)}=4.14 \\
P=0.0063\end{array}$} \\
\hline 5-14 years & 222 & 72.29 & $62.82-83.21$ & \\
\hline 15-45 years & 361 & 87.32 & $77.64-97.93$ & \\
\hline$>45$ years & 76 & 66.01 & $53.78-81.00$ & \\
\hline \multicolumn{5}{|l|}{ Sex } \\
\hline Male & 314 & 74.32 & $66.09-83.57$ & \multirow{2}{*}{$\begin{array}{c}t_{(749)}=0.75 \\
P=0.455\end{array}$} \\
\hline Fernale & 437 & 78.80 & $71.35-87.02$ & \\
\hline \multicolumn{5}{|l|}{ Occupation } \\
\hline Unemployed & 67 & 89.13 & $69.28-116.6$ & \multirow{6}{*}{$\begin{array}{c}F_{\text {贷.741 }}=2.94 \\
P=0.0123\end{array}$} \\
\hline Housewite & 223 & 81.36 & $70.60-93.24$ & \\
\hline Student & 192 & 65.61 & $56.98-75.58$ & \\
\hline Fishermen & 131 & 95.46 & $78.32-116.33$ & \\
\hline Child (preschool) & $\infty$ & 00.74 & $45.04-90.90$ & \\
\hline Others & 96 & 65.99 & $53.98-80.22$ & \\
\hline
\end{tabular}

-There were 751 valid cases for intensity of infection. cFour cases with missed occupation.

beven cases with missed age. "Both sexos.

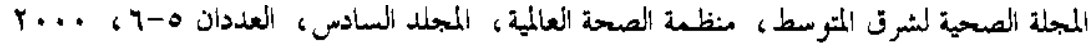


The overall prevalence rate of heterophyiasis in our study population was $33.8 \%$ and the calculated $\mathrm{CI}$ was 27.89-39.71. Figure 2 shows that in $11.0 \%$ of the studied families, the intrafamilial prevalence rate was within the $95 \% \mathrm{CI}$ of the overall prevalence in the study population, while in $89.0 \%$ of the families the prevalence was below or above the $95 \% \mathrm{CI}$.

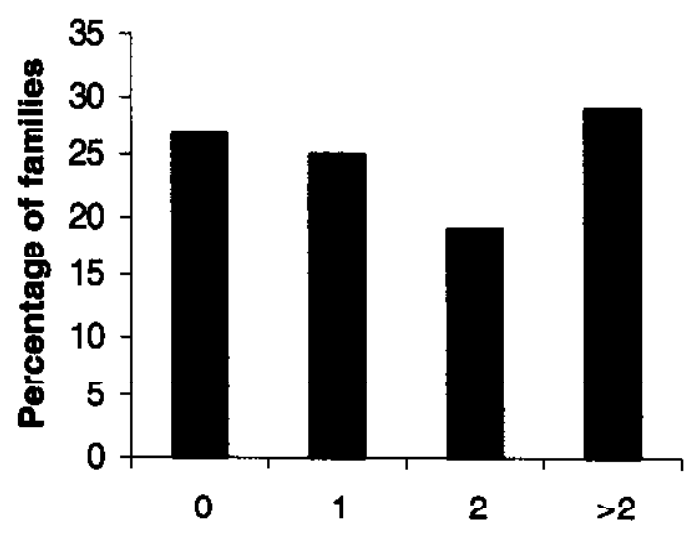

Number of people in the famlly

Figure 1 Percentage distribution of the families according to the number of infected persons within the family.

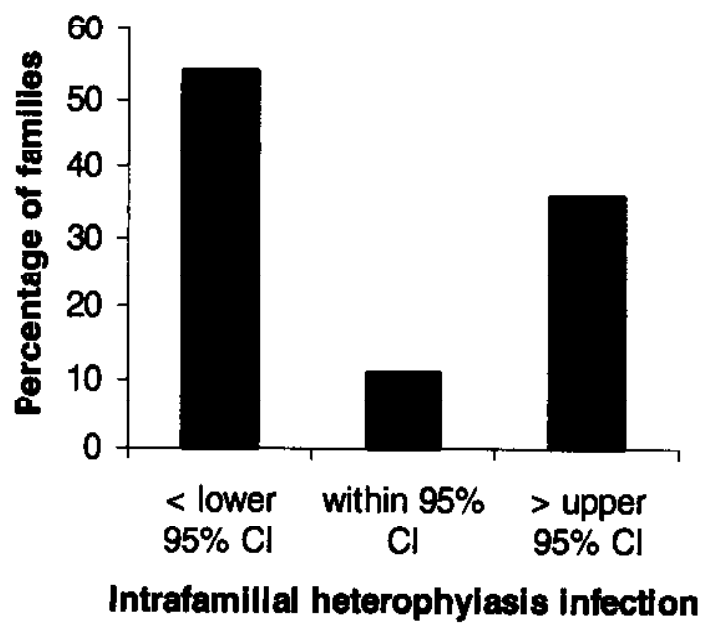

Figure 2 Distribution of the families according to the relation to the $95 \%$ confidence intervals (C) of the overall prevalence of heterophylasis. 


\section{Discussion}

In general, parasitic infections in El-Meaddeya village werc found to be very high, affecting $84.7 \%$ of the population. A study on the possible association with socioeconomic parameters and available sanitary facilities, housing conditions and food habits in El-Meaddeya village is needed to identify the possible causes of this high rate of parasitic infection.

In our study, the most impressive finding was the strikingly high prevalence of heterophyiasis, as more than one-third $(33.8 \%)$ of the inhabitants were found to be infected. This figure is higher than that reported by El-Morshidy et al. [7] who reported in Baltim city, Kafr ash Shaykh govemorate, a prevalence rate of $13.5 \%$, and that of Rifaat et al. [8] who reported a prevalence rate of $5.1 \%$ in El-Matarria, Daqahliyah governorate and that of Yousef et al. who reported a prevalence rate of $5.0 \%$ in the outpatient department of a local hospital in Lake Edku [9].

Many fish have been described as intermediate hosts for Heterophyes, such as $M$. cephalus, $M$. auratus, Tilapia nolitica and T. zilli $[3,10]$. All of these types of fish were found in El-Meaddeya and the villagers ate all types and sizes of these fish either grilled or salted for 1-2 days [5]. This could explain the high prevalence rate of heterophyiasis.

Because both heterophyiasis and other parasitic infections were so common in the study village, an individual suffering from combined infection was the rule rather than the exception.

Despite the fact that the highest prevalence of heterophyiasis was found in the age group $15-45$ years $(37.3 \%)$, the prevalence, even in young children $(<5$ years), was unexpectedly high $(27.9 \%)$. These findings should stimulate planning activities to raise public awareness about the mode of transmission of heterophyiasis and the importance of food hygiene. Also, the possible health impact of heterophyiasis on these children requires special attention. Subjective abdominal complaints, malabsorption, anorexia, vomiting and/or diarrhoea are among the possible signs to search for.

Heterophyiasis was more common in females than in males $(36.7 \%$ versus $30.5 \%$ ). El-Morshidy et al, recorded that the prevalence of heterophyiasis in Kafr ash Shaykh governorate was $13.5 \%$ and it was higher in females $20-34$ years $(17.3 \%)$ than males $(13.5 \%)$ [7]. This is probably due to exposure to infection by females through handling, preparing and tasting of fish during cooking and processing, as it contains living larvae. This is also in agreement with the study of Nagaty and Khalil who reported prevalence rates of $14.5 \%$ and $22.3 \%$ among males and females respectively $[11]$.

The intensity of heterophyiasis was highest in people 15-45 years (mean egg count 87.32 , CI: 77.64-97.93). Intensity of infection was slightly higher in females than males and was highest in fishermen. The differences in the probability of becoming infected and the intensity of infection, whether by age, sex or occupation, were mostly attributed to variation in food habits.

Our study identified high intrafamilial aggregation of heterophyiasis as proven by the percentage of families $(84.7 \%)$ in which the intrafamilial prevalence rate was below or above the $95 \% \mathrm{CI}$. This indicates that cases of heterophyiasis were not randomly distributed throughout the study population, but were aggregated in families. This is in accordance with the work of ElMorshidy et al., who reported clustering of cases of heterophyiasis in the same family due to sharing of food [7].

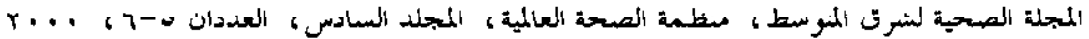


As heterophyiasis in El-Meaddeya is so prevalent, training of laboratory technicians in local health units to improve their diagnostic skills is warranted. It can be concluded that transmission of heterophyiasis in Egypt is continuous, especially in the vieinity of lakes with brackish water. Furthermore, we cannot ignore the role of fish caught from El-Meaddeya as a source of heterophyiasis since a large proportion of the population consumes fish.

\section{Acknowledgements}

This study was financed by Consorzio per lo Sviluppo della Medicina Tropicalc (CMT), Italy within the framework of the Egyptian-Italian Cooperation Ptoject. The authors would like to thank Dr Elil Renganthan, World Health Organization, and Dr Claudia Gandin, CMT coordinator, for their support during the preparation of the study.

\section{References}

1. Schmidt GD, Robert LS. Foundations of parasitology, 4th ed. St Louis, Times Mirror/Mosby, 1989.

2. El-Makaddem A. The prevalence of heterophoids in man, animals and various fish hosts in Edku area [Thesis]. Alexandria, Egypt, University of Alexandria, 1982.

3. Taraschewski $H$. Investigations on the prevalence of Heterophyes species in twelve populations of the first intermedjate host in Egypt and Sudan. Journal of tropical medicine and hygiene, 1985, 88(4):265-71.

4. El-Sahly $\mathbf{A M}$ et al. Intestinal helminthic and protozoal infections and urinary schistosomiasis in Egyptian children. Journal of the Egyptian Society of Parasitology, 1990, 20(1):9-21.

5. Abou Basha LM. Use of parasite species composition indices of fish to measure the edge of environmental deterioration due to pollutants and other man-made adverse effects. Final report of Avicenne Initiative Project (Contract AVICT 920001) sponsored by the European Commission, 1999.
6. Martin LK, Beaver PC. Evaluation of Kato thick-smear technique for quantitative diagnosis of helminth infections. American journal of tropical medicine and hygiene, 1968, 17(3):382-91.

7. El-Morshidy $\mathrm{HN}$ et al. A study of heterophoid infection in Kafr ash Shaykh Governorate. Menoufia medical journal, 1994, 6(2):289-300.

8. Rifaat MA et al. Studies on the incidence of Heterophyes heterophyes in Daqahliyah Governorate. Iournal of the Egyptian Society of Parasitology, 1980, 10:369-73.

9. Yousef MM ot al. Heterophoid parasites of man from Edku, Mariyut and Manzala lakes areas in Egypt. Journal of the Egyptian Society of Parasitology, 1987, 17:475-9.

10. Khalil M. The history of human trematode parasite Heterophyes in Egypt. Lancet, 1933, 2:225-37.

11. Nagaty HF, Khalil HM. Incidence of helminth infection among the outpatients in the clinic of Mattaria collective unit, Daqahilyah Governorate, Egypt. Joumal of the Egyptlan Medical Association, 1964, 47:341-6. 